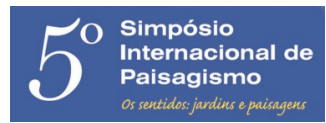

\title{
O jardim dos sonhos
}

\author{
RAUL CÂNOVAS (1)
}

\section{RESUMO}

O jardim dos sonhos sempre foi um ideal dos homens. No Antigo Egito, já se falava em um jardim sempre verde para onde as pessoas de bom coração iam após a morte. E na mitologia grega, um lindo jardim era palco das festas bucólicas dos deuses. As grandes religiões também citavam jardins como paraísos, como o Jardim do Éden. Neste artigo, Raul Cânovas nos leva a refletir sobre o sentido de um "jardim perfeito", sem tratar a perfeição como apenas plástica e estruturada com exatidão, mas referindo-se a um jardim que nos inspire e emocione, emancipado de modismos passageiros. O paisagista também nos alerta sobre as condições mutáveis de um jardim, que nunca está finalizado. O paisagismo não é apenas técnica; é também sensibilidade, utilidade, sustentabilidade e equilíbrio das forças da natureza.

Palavras-chave: paisagismo, paisagista, Cânovas, Éden.

ABSTRACT

\section{The garden of the dreams}

The garden of the dreams always was an ideal of the men. In the Old Egypt, already was spoken in an always green garden for where the goodhearted persons went after death. And in the Greek mythology, a pretty garden was stage of the bucolic parties of the gods. The big religions also cited gardens as heavens, like the Garden of the Eden. In this article, Raul Cânovas takes us to a reflection about the sense of a "perfect garden", without refer to the perfection as just plastic and structured with accuracy, but referring to a garden that inspires and excites us, emancipated of the ephemeral vogue. The landscape designer also alerts us about the changeable conditions of a garden, that never is finalized. The landscape design is not barely technical; is also sensibility, utility, sustainability and equilibrium of the forces of the nature.

Keywords: landscape design, landscape designer, Cânovas, Eden.

O Jardim do Éden é o lugar onde estão guardados todos os mistérios. Lá - e isso é percebido de modo atávico - ficaram olvidados nossos anseios verdadeiros, nossa razão primordial de existir. Diria até que um atributo essencial foi perdido no exato momento em que o dedo divino indicou, em riste, a saída derradeira.

Talvez esse atributo, que fazia parte da essência do casal, aquilo sem o qual não poderia existir, pois era da própria natureza adâmica, extinguiu-se nesse instante.

Esse Paraíso Divino não é exclusivo da iconografia judaico-cristã. No Antigo Egito, depois de passar pelo tribunal de Osíris, os mortos tinham seus corações colocados em uma balança para serem pesados - tendo como contrapeso uma pena de avestruz. Em seguida, o resultado era anotado por Thot e apresentado a Osíris por Hórus, e aquele cujo coração fosse tão ou mais leve que a pluma era conduzido até as portas do Sekhet-Aaru, o campo de juncos macios e sempre verdes onde moraria, eternamente, protegido de qualquer mal. Também a mitologia grega se preocupava com a vida eterna, especialmente com aquela que era prometida às boas almas.

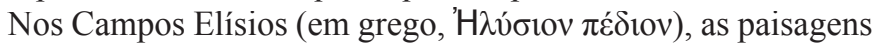
eram verdejantes, salpicadas de ciprestes e de canteiros de narcisos, imaculadamente brancos ou dourados, que alegravam os que lá habitavam. Nesse lugar, o Hospitaleiro, como era conhecido o deus Hades, organizava festas bucólicas, nas quais se ouviam flautas campestres e se dançava.

O jardim paradisíaco foi, desde sempre, a base de nossos sonhos. A origem da palavra "paraíso" é persa, derivada de "pairi-daeza", que significa "local cercado", e foi transliterada para o hebraico três vezes no Antigo Testamento (Cântico dos Cânticos 4:13, Eclesiastes 2:15, Neemias 2:8). É também interessante encontrar no texto do Alcorão as revelações que Alá fez a Maomé. No $2^{\circ}$ Sura, em seu $25^{\circ}$ Ayat, diz: "anunciem a boa nova aos que acreditam e ajam de modo certo: terão jardins, onde nos vales correrão rios. Sempre que se lhes dê como sustento um fruto deles, dirão: é igual ao que comemos antes. Terão esposas puras (huríes) e permanecerão ali eternamente". No Alcorão, emprega-se, sistematicamente, a palavra árabe al-channa, cuja tradução literal é "jardim". Também é utilizada a palavra Jannat com o mesmo significado: jardins com tamareiras, jasmins e romãzeiras cheias de folhagem verde, com todas as frutas criadas, e com fontes de águas frescas. Lá, as pessoas estarão recostadas sobre tapetes e almofadas forradas de brocado, e os frutos do jardim

(1) Paisagista. raulcanovaspaisagista@uol.com.br. 
estarão ao alcance da mão. Viverão entre lotos sem espinhos, bananeiras, águas e frutas em abundância inesgotável, que nunca lhes serão proibidas.

Andando um pouco mais, em direção ao Leste, chegamos ao Extremo Oriente, onde o xintoísmo surge no século III a.C., adorando a natureza e os ancestrais. No Japão, as pessoas, depois da morte, podem se transformar em Kamis, um grande complexo de divindades, se personificar como árvores e riachos, e através deles serem lembrados, cultuados e venerados.

É notável como, de um modo ou de outro, sonhamos com o jardim excelso e sublime, e nos esforçamos na tentativa sempre infrutífera de recriar o Éden. Não entendemos que além da paisagem que nossos olhos conseguem enxergar existe o infinito e, talvez por covardia ou simplesmente pela mediocridade amarrada às tradições clássicas, nos sentimos impedidos de inovar. Assim, desenhamos jardins desapaixonados como soles de junho, que emitem alguma luz, mas não aquecem.

Quantas vezes somos condenados a deitar nossos olhos em cima de jardins mumificados, com plantas imóveis, sentenciadas a uma eterna rigidez pelo paisagista que transformou arte em ofício, técnica em comércio, e prazer em insipidez. Esse profissional, quando íntegro, vive graças a certa dose de fantasia, que se sobrepõe ao que existe e é real; sonha com espaços salutares nos quais seus "atores" fincaram raízes no verdadeiro e na harmonia. O jardim sonhado pelo mestre alimenta os sentidos, sugere que fechemos os olhos e sintamos o bem que nos proporciona. É muito mais do que belo... É bom! E é bom porque não podemos conceber que a mágica que fabricamos junto às forças da natureza possa resultar apenas em algo puramente bonito; esse pedaço de verde deve revelar o jardim escondido no recanto do nosso "Eu" verdadeiro, e não precisa (e não deve) ser "clean" ou neoclássico. Deve emancipar-se do rebanho e dos dogmas impostos pelos modismos efêmeros e passageiros, e exibir a fugacidade da vida com todas suas alegrias, mas também com seus inexoráveis momentos que mostram a fragilidade de uma árvore frente à tormenta, ou o suplício da begônia sob o sol tórrido.

O jardim dos sonhos nos serve de modelo para entender o sentido da vida. Muitas vezes, coloca-nos frente a uma tímida gota de orvalho, em lugar de uma roseira florida e fragrante, apenas para nos ensinar que devemos ficar atentos às pequenas coisas. A final de contas, a aquileia, o tomilho, a hortelã, o boldo e a arruda, apesar da aparência discreta, quase insignificante, trazem prazeres e benefícios, enquanto que a rosa nos alfineta com seus acúleos.

Sonhar é como olhar para dentro de nós mesmos, e assim percebermos nossas consciências, que em seu âmago habita Deus: manes in memoria mea. E através de nossas quimeras entramos em contato com a paisagem perfeita, ou quase isso, porque é impossível lograr uma que tenha sido finalizada, de modo cabal e magistralmente, e que não se possa aperfeiçoá-la. Fantasiar o jardim insuperável equivale a imaginar um príncipe encantado sobre um cavalo branco, vestido com capa púrpura e coroa. Toda moça sonha com ele desde seus doze, treze anos de idade, e supõe encontrá-lo algum dia, não importa quando, não importa como. E mesmo que a figura desse príncipe o revele andróide e irreal, o primogênito do rei será o protagonista das divagações dessa moça pelo resto de sua vida. No fundo, ela sabe da impossibilidade de concretizar seus delírios amorosos, a ponto de se resignar e entregar seu amor a alguém de carne e osso.

Com o jardim dos sonhos acontece algo similar, ele possui ingredientes fantásticos: palmeiras que beijam as nuvens, deixando-lhes gosto de tâmaras; bambus que coreografam "O Lago dos Cisnes", surpreendendo o próprio Tchaikovsky; e flores vestidas de festa, com cores ainda não descobertas. Delírio? Não, apenas sonho, um sonho que é substituído por um pedacinho de verde inventado da melhor forma possível. Entretanto, não devemos ficar decepcionados por não realizarmos esses sonhos, pelo contrário, precisamos mostrar nossa gratidão por sermos recompensados com algo vital: a capacidade de sonhar. Enquanto sonhamos, idealizamos formas que impedem que a paisagem bucólica herdada seja destruída por uma civilização industrial impiedosa. É um tanto irônico concluir que nunca se falou tanto de paisagem como agora. Desde o Renascimento, falamos e falamos na tentativa de buscar uma forma, uma identidade, algo que nos proporcione um feliz bem-estar. Contudo, a elite letrada que engendrou o pensamento paisagístico evoluiu "rococosamente" em direção ao falso refinamento, rotulando de sofisticado aquilo que é pleno de artificialismo. Às vezes pecamos com meras cenografias apelidadas de "clean", esquecendo-nos que a proposta é devolvermos a paisagem perdida, e não arquitetarmos uma lavanderia.

Ao que tudo indica, não estamos construindo paisagens eficientes - pelo menos, isso é o que as metrópoles, cada vez mais febris, mostram. Creio que nosso equívoco radique no afastamento desse sonho e na perda do atributo inerente, que nos ensinava a contemplar o contorno de modo divino e presencial.

Esquecemos de notar como os vales, eternamente férteis, originaram vida: o de Yangtzé, na China; o que é formado pelo Nilo, no Egito; o do Delta, Ganges e Indo, na Índia; e o vale, outrora fertilíssimo, formado pelos rios Tigre e Eufrates. Nós, humanos, como que plagiando o planeta, nascemos do vale materno, que tanto se parece com aqueles outros que parem tantas formas de vida.

Precisamos entender mais e melhor nosso contorno, não morfologicamente, tampouco de maneira biológica, pois, apesar de importantes, já foram exaustivamente estudados. É necessário vivenciarmos uma relação íntima com aquilo que nos rodeia para não nos distanciarmos daquele palco fantástico que nos foi deixado, e onde atuamos, representando a peça fundamental que se intitula "existência".

Cuidado com a imitação conservadora, com a repetição automática, pois isso transforma a arte da paisagem em rotina perigosa, onde os perfumes são ignorados ou apenas descritos pelos livros de botânica, mas que nunca foram percebidos de maneira olfativa. O medíocre não se compromete com romantismos, esforça-se em ser chique e, a duras penas, consegue não ser vulgar; no entanto, não se comove com a originalidade, pelo contrário, a teme; nunca inventa nada, não procura novos paradigmas e, em contrapartida, guarda com 
zelo os dogmas estéticos acumulados durante séculos.

Mas o paisagismo, como arte aplicada, exige mecanismos que o vivificam e o colocam novamente como algo a ser sonhado, algo parecido com o que os guaranis chamam de $Y v y$ Mara e'y, que significa “Terra sem mal”, um lugar localizado do outro lado do rio e que promete uma vida melhor.

$\mathrm{O}$ jardim dos sonhos é um conjunto de realidades extradivinas que encerram o segredo da Criação, assim como o Jardim do Éden deve ser o ponto de partida para alcançar, no final da caminhada, um bem supremo: a felicidade. $\mathrm{O}$ combustível para essa viagem é a paixão. Esse jardim possui algo fundamental que, em 1750, Baumgartem chamou de estética - a perfeição do conhecimento sensorial que se contrapõe ao conhecimento intelectual -, tendo a beleza como arma. Talvez não seja real, pois o real é concreto, palpável, mas existe, porque está dentro de nós.

Tudo isso me fez lembrar um filme de Akira Kurosawa, que assisti no inicio da década de 1990, chamado "Sonhos" ("Dreams" - título original em inglês). Ele é dividido em oito histórias, uma delas, "Corvos", mostra o alter-ego do cineasta correndo em Auvers-sur-Oise, a última das pinturas de Van Gogh, no Sul da França, à procura do pintor. No quadro, lavadeiras, retratadas por Van Gogh, ao lado da ponte onde passa uma carruagem, comentam que ele é um louco perigoso e que havia ficado internado até poucos dias antes. Kurosawa corre ao encontro do mestre (interpretado pelo cineasta Martin Scorcese, fã do diretor japonês). Na última cena desse sonho, Akira Kurosawa surge abaixando a cabeça e tirando o chapéu diante da tela "Campo de Trigo com Corvos". Nunca me esqueci dessas imagens, em que o cineasta libera seus devaneios, mergulhando na obra derradeira desse impressionista holandês que entendia a paisagem de maneira tão peculiar.

Entretanto, devo concordar que hoje o desenhista de jardins precisa de algo mais do que visão artística e sensibilidade. A técnica paisagística, por ser uma arte aplicada, isto é, uma atividade em que se procura não apenas um resultado estético, mas também funções de utilidades com benefícios objetivos devem levar em conta diferentes técnicas, ou ciências, como: biologia, botânica, engenharia agronômica e florestal, fitopatologia, edafologia, fitogeografia e topografia. Esses conhecimentos mencionados eram suficientes até o início do século XX, quando a população mundial era de 1.650 milhões de habitantes; hoje, somos quase sete bilhões de seres humanos, dos quais mais de 50\% habitam centros urbanos, por esse motivo, é necessário, igualmente, possuir conceitos e teorias que organizem os espaços de forma a adequar o paisagismo à realidade urbanística, bem como as tendências arquitetônicas de cada metrópole. $\mathrm{O}$ conhecimento intelectual da arquitetura, do urbanismo, da matemática e da história é fundamental, como também são essenciais a sociologia, a psicologia, o folclore e, por que não, as crenças religiosas de cada região onde a área verde será inserida.

O ser humano, em constante evolução, precisa de paisagens dinâmicas que o complementem psiquicamente, dando-lhe equilíbrio. Por isso, devemos pensar em novos paradigmas, já que os modelos criados pelos célebres paisagistas dos últimos cinco séculos, Giacomo da Vignola, André Le Notre, Humphry Repton, Frederick Olmsted e Thomas Church, apesar de profundamente inspiradores, necessitariam hoje de um processo evolutivo na busca de soluções para as questões suscitadas nas sociedades do século XXI.

Porém, concluo dizendo que eles usufruíam do mais importante atributo que um criativo precisa ter: o dom de sonhar, ainda que acordados.

\section{BIBLIOGRAFIA CONSULTADA}

ABRÃO, B. S. Dicionário de Mitologia. São Paulo: Editora Best Seller, 2000.

ALMEIDA, J. F. Bíblia Sagrada. São Paulo: Sociedade Bíblica do Brasil, 1995.

ANGLADE, P. El Gran Libro de la Jardineria. Leon: Editorial Everest, 1994. 620p.

APARICIO, M. C. Dioses, Mitos y Heroes de la Humanindad. México: Ediciones Palov. 576p.

BERQUE, A. EI pensamiento paisajero. Madrid: Editorial Biblioteca Nueva, 2009. 134p.

CADENA, F. P. Historia de los Estilos en Jardinería. Madrid: Ediciones Istmo, 1998.

CLIFFORD, D. Los Jardines, Historia Trazado, Arte. Madrid: Instituto de Estudios de Administración Local, 1970. $247 \mathrm{p}$.

ELLIS, N. Deusas e Deuses Egípcios. São Paulo: Madras Editora, 2003. 342p.

GUELlOUZ, A. O Alcorão. Porto Alegre: Editora Instituto Piaget, 2002. 128p.

HINNELLS, J. R. Dicionário das Religiões. São Paulo: Editora Cultrix Ltda, 1990.

INGENIEROS, J. El Hombre Mediocre, México, Editorial Porrua S.A, 2008. 185p. 